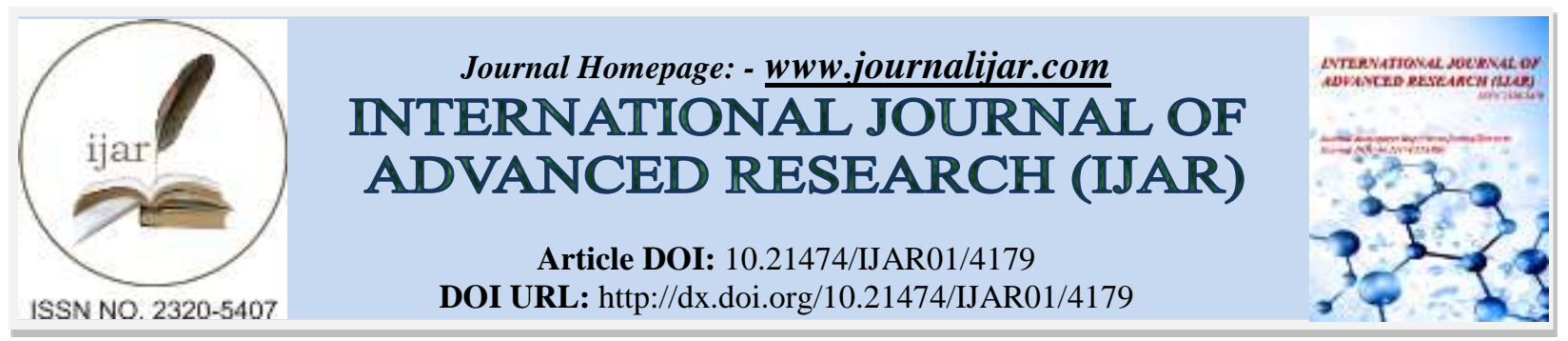

RESEARCH ARTICLE

\title{
ACQUAINTANCE AND CONCEPTION ABOUT BIOSTATISTICS AMONG POSTGRADUATE STUDENTS IN TAMILNADU.
}

Rini joy, Shamili m², R. Ganesh and A H Harini Priya*

Department of Public Health Dentistry, Priyadarshini Dental College and hospital, Thiruvallur, Tamil Nadu, India;

\section{Manuscript Info}

\section{Manuscript History}

Received: 12 March 2017

Final Accepted: 16 April 2017

Published: May 2017

Key words:-

Postgraduate Dental students,

Biostatistics, Research.

\section{Abstract}

Aim: The main aim of this study was to determine the perception and attitude of postgraduate dental students in Tamilnadu towards Biostatistics.

Materials and methods: The study was conducted among the Postgraduate Dental students belonging to six different private Dental colleges in Tamil Nadu. A validated structured questionnaire was distributed among 285 Postgraduate Dental students and 253 students responded. The data so collected was analyzed using SPSS software version 16.0. SPSS software version 16.0.

Results: Results showed that all postgraduate students were aware about the importance of biostatistics in the field of research but they flatter in the application aspect of the same in the field of research and were reliant on experts.

Conclusion: The Dental students should be trained in the field of biostatistics during their undergraduate training period. Biostatistics is the portal for research, which needs to be given due care to shape them, to make them experts in the field of research.

Copy Right, IJAR, 2016,. All rights reserved.

\section{Introduction:-}

Evidence based dentistry holds the upper hand in today's practice. It is challenging for dental professionals to cope with the recent advances in the field of science and technology and they need to update with scientific literature for the betterment of both clinical and research skills. In order to sense the outcome of the innumerous research projects conducted in the field of research, on needs to master biostatistics which is a decisive tool for precise understanding of scientific literature and including it as a part of the dental curriculum is gaining profound importance in recent era.

Statistics is the science of collecting, analyzing and obtaining inference from data. Countenance of statistics varies based on its field of application. Scrutinizing a data on statistical terms makes it more significant. And It plays a pivotal role in conveying the output of the study and impart research findings, it gives credibility to research methodology and conclusions. Understanding the research findings either directly or indirectly affects the clinical aspect of the field as such.

As formerly mentioned Biostatistics is a branch of applied statistics which deals with the statistical evaluation of preliminary or advanced research or clinical trials. Which is an integral part of both dental and medical sciences as research paves way for improved diagnostic and treatment modalities which in turn can improve the quality of life 
for each and every patient. Skimpy knowledge about this imperative sector of research can contravene the quality of research. (1) Indecorous application of statistical techniques not only results in time and loss of tremendous efforts but can also wreck humanity. (2) Legitimizing individuals with statistical thinking to improve the scope of research projects is the main goal of statistical training. Most Health care professionals inclusive of dentists agree to the fact that statistical knowledge is essential to stand out as an exceptional in evaluating scientific literature. (3) However assessment of statistical knowledge of medical clinicians has shown minimal improvement during the past decades suggesting the lack of training so underwent by the individual which is attributed to various factors. (4) The disparate background, field of interest be it research or clinical oriented, type of exposure towards the field of interest, knowledge of the trainer all of these have an ambiguous effect on repercussion about statistics. Which in turn advocate a modified training methodologies to improve the students or professionals interest in the province of statistics. (5) Thus, objective of this study was to assess the awareness and attitude of postgraduate dental students in Tamilnadu pertaining to purview of biostatistics in the field of research.

\section{Materials and Methods:}

This cross-sectional study was conducted among Postgraduate Dental students in Tamilnadu. The study was approved by Institutional Review Board (IRB) of Priyadarshini Dental College and Hospital and the permission to conduct the study was obtained from Institutional Ethical Committee of Priyadarshini Dental College and Hospital. Out of seventeen Dental colleges with Post graduation in Tamilnadu, six colleges were randomly chosen for conducting the survey. A sample size of 202 was obtained based on $90 \%$ power with an alpha error 0.05 . Sample size was estimated by using G Power Statistical Software.

Data collection was done using pretested questionnaire. The questionnaire had dichotomous [yes/no] responses. A total of 285 postgraduate dental students were surveyed and $253(90 \%)$ of them responded. There were 21 closed ended questions. The Questions were so framed to assess the level of understanding, application, difficulties faced in using statistics while handling a research project. Demographic data were also recorded on the same day. Scoring was based on the responses to 21 closed ended questions.

\section{Statistical Analysis:}

Percentage and Frequency distribution was calculated for all variables such as gender, branch and questions. $\mathrm{P}<0.05$ was considered to be statistically significant.

Mann-Whitney test which is a non-parametric test was used to test if there was significant difference across gender. Kruskal-Wallis test, a non-parametric test was used to test if there was significant difference across branches in dentistry. SPSS software version 16.0 was used for statistical analysis. 
Figure 1:- Distribution Of Study Subjects Across Branches In Dentistry.

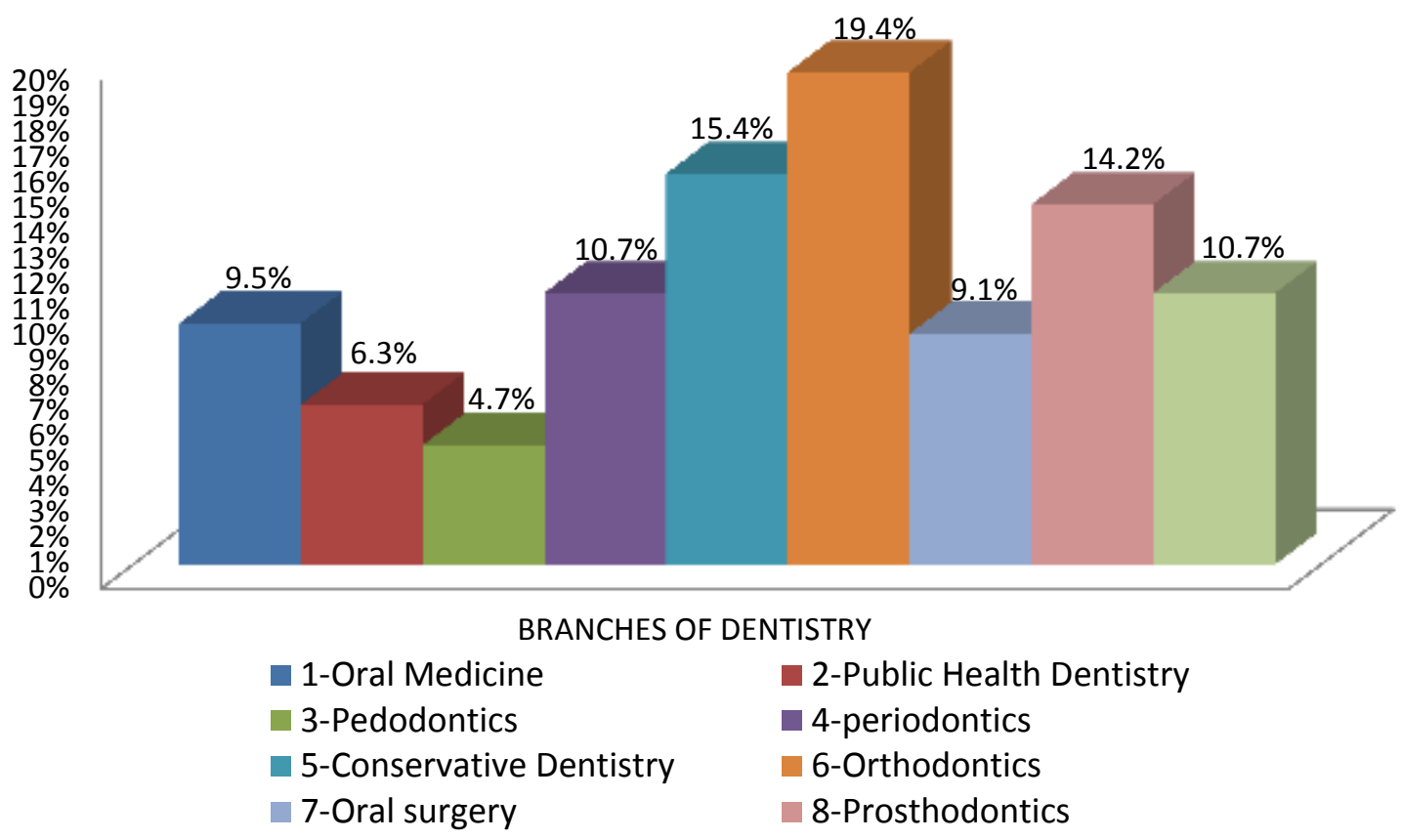

Table 1:- Awareness And Perception Of Study Subjects Towards Biostatistics

\begin{tabular}{|c|l|c|c|c|}
\hline \multicolumn{1}{|c|}{ QUESTION } & \multicolumn{1}{|c|}{ RESPONSE RATE } \\
\hline S.NO & \multicolumn{1}{|c|}{$\begin{array}{c}\text { YES } \\
\text { N(\%) }\end{array}$} & $\begin{array}{l}\text { NO } \\
\text { N(\%) }\end{array}$ & $\begin{array}{l}\text { NOT ANSWERED } \\
\text { N(\%) }\end{array}$ \\
\hline 1 & $\begin{array}{l}\text { Are you aware about the importance of } \\
\text { Biostatistics? }\end{array}$ & $228(90.1)$ & $25(9.9)$ & - \\
\hline 2 & $\begin{array}{l}\text { Do you have basic knowledge about the } \\
\text { concepts in Biostatistics? }\end{array}$ & $202(79.8)$ & $51(20.2)$ & - \\
\hline 3 & $\begin{array}{l}\text { Is Biostatistics a part of your curriculum } \\
\text { during Post graduation? }\end{array}$ & $193(76.3)$ & $60(23.7)$ & $64(25.3)$ \\
\hline 4 & Are there faculties to teach Biostatistics? & $113(44.7)$ & $76(30.0)$ & $64(25.3)$ \\
\hline 5 & $\begin{array}{l}\text { Are the faculties interested in teaching } \\
\text { Biostatistics? }\end{array}$ & $131(51.8)$ & $58(22.9)$ & - \\
\hline 6 & $\begin{array}{l}\text { Are you interested in learning } \\
\text { Biostatistics? }\end{array}$ & $188(74.3)$ & $65(25.7)$ & $64(25.3)$ \\
\hline 7 & $\begin{array}{l}\text { Training in Biostatistics during my } \\
\text { course is adequate for my needs }\end{array}$ & $124(49.0)$ & $65(25.7)$ & - \\
\hline 8 & $\begin{array}{l}\text { Do you think Biostatistics } \\
\text { is useful? }\end{array}$ & $234(92.5)$ & $19(7.5)$ & - \\
\hline 9 & $\begin{array}{l}\text { Statistics is worthwhile in part of your } \\
\text { study }\end{array}$ & $223(88.1)$ & $30(11.9)$ & - \\
\hline 10 & $\begin{array}{l}\text { Can statistical analysis of your study be } \\
\text { performed on your own? }\end{array}$ & $72(28.5)$ & $181(71.5)$ & - \\
\hline 11 & Statistics is best to be left to the experts? & $210(83.0)$ & $43(17.0)$ & - \\
\hline 12 & $\begin{array}{l}\text { Have you participated along with the } \\
\text { experts in the analysis? }\end{array}$ & $97(38.3)$ & $156(61.7)$ & - \\
\hline 13 & $\begin{array}{l}\text { Training in statistics will make me better } \\
\text { professional? }\end{array}$ & $200(79.1)$ & $53(20.9)$ & - \\
\hline 14 & Statistics training is very mysterious and & $185(73.1)$ & $68(26.9)$ & - \\
\hline
\end{tabular}




\begin{tabular}{|l|l|c|c|c|}
\hline & too complicated? & & & \\
\hline 15 & Statistics is math oriented & $201(79.4)$ & $52(20.6)$ & - \\
\hline 16 & $\begin{array}{l}\text { Statistical thinking is an important } \\
\text { characteristic of good research }\end{array}$ & $239(94.5)$ & $14(5.5)$ & - \\
\hline 17 & Statistics is the science of uncertainty & $128(50.6)$ & $125(49.4)$ & - \\
\hline 18 & $\begin{array}{l}\text { It is unreasonable to expect the average } \\
\text { professional to master and apply } \\
\text { statistics }\end{array}$ & $144(56.9)$ & $109(43.1)$ & - \\
\hline 19 & $\begin{array}{l}\text { Is it difficult to understand and write the } \\
\text { statistical section of the study? }\end{array}$ & $191(75.5)$ & $62(24.5)$ & - \\
\hline 20 & $\begin{array}{l}\text { Do you feel that you have better } \\
\text { knowledge about Biostatistics during } \\
\text { Post graduation than during under } \\
\text { graduation }\end{array}$ & $220(87.0)$ & $33(13.0)$ & - \\
\hline 21 & $\begin{array}{l}\text { Statistics become more understandable } \\
\text { and useful after applying it in my career }\end{array}$ & $223(88.1)$ & $30(11.9)$ & - \\
\hline
\end{tabular}

Table 2:- Questions which had statistically significant difference as answered by Men and Women.

\begin{tabular}{|c|l|c|}
\hline S.NO & \multicolumn{1}{|c|}{ QUESTIONS } & \multicolumn{1}{|c|}{ P VALUE } \\
\hline 1. & Are you interested in learning Biostatistics? $*$ & 0.007 \\
\hline 2. & $\begin{array}{l}\text { Training in Biostatistics during my course is adequate for my } \\
\text { needs. } *\end{array}$ & 0.043 \\
\hline 3. & $\begin{array}{l}\text { Statistics become more understandable and useful after applying } \\
\text { it in my career. } *\end{array}$ & 0.035 \\
\hline
\end{tabular}

* - Mann Whitney test

$\mathrm{P}<0.05=$ Statistically significant.

\section{Results:}

A total of 253 Postgraduate dental students participated in the study. Out of 253 Postgraduate dental students, $123(48.6 \%)$ were males and $130(51.4 \%)$ were females. Figure.1 shows distribution of Postgraduate Dental students who participated in the study, across various branches in Dentistry. Table 1 shows the perception of students in regards to training so obtained in the field of biostatistics and the efficiency of exploiting them in their research projects. Table 2 shows the data, which showed significant difference among men and women, where in women who took part in the study tend to show more interest towards statistics compared to men.

\section{Discussion:}

Statistics fulfills a substantial role in scientific method taking into account the organization, description, analysis and interpretation of the data and thus becomes a valuable tool in evidence based dentistry. Its proper use converts scientific assumptions into proven facts. (3)

In our study, most of the respondents (90\%) are aware about the priority of biostatistics and agree to the fact that it is of utmost important in the field of research. They also agree to the fact that it plays a pivotal role in diagnosis and treatment planning I various scenarios. This is mainly attributed to the integral part of research in post graduate training program.

Our study shows that Biostatistics is a part of the curriculum for most of the Postgraduate students (76\%). Though it has been included as part of training program, the efficacy with which it is employed is comparatively less, only few (28\%) have the confidence to perform statistical analysis of their study on their own. This was in accordance with the results so obtained by Shetti et al. (6) To overcome this a possible solution as given by Ramisetti et al, according to which Lectures and continuing dental education (CDE) programs highlighting the importance, increasing the knowledge and application of Bio statistical principles by postgraduate students in research should be conducted both at basic and advanced level. (3)

Our study shows that most of the respondents (83\%) accept that Statistics is best to be left to the experts. This result is in agreement with Ramisetti et al who concluded that authors of dental publications rely upon professional 
statisticians who are experts in the field and have more than just a casual familiarity with dentistry and that dependence on professional statistician might be due to incomplete knowledge about Biostatistics. Our study also reveals that most of the respondents $(80 \%)$ feel that Statistics is more oriented towards mathematics. The reason for all these is due to the negative stance that Biostatistics is influenced only by strong base in mathematics and computer skills.

This study also reveals the paucity of trained faculties to enlighten Biostatistics (30\% respondents agree to this point and $25 \%$ respondents have not answered) along with the negligence of the faculties to teach (23\% respondents agree to this point and $25 \%$ respondents have not answered) has led to the present outlook towards Statistics.

But even if faculties with competent of statistics knowledge are available, they lag behind when it comes to catering statistical concepts to the dental professionals. (7) Also, many biostatisticians are unaware that Evidence Based Dentistry (EBD) is an ideal vehicle for importing knowledge about biostatistics. $(8,9)$ Proper channel to unravel the limitations in teaching biostatistics is to incorporate problem based training methodology as a part of intense biostatistics training program and also student-centered approach much be encouraged, to improve substantial student involvement and also surge the interest in the field of biostatistics and its application in the province of research.(10) According to a study done by Batra et al there was a statistical significant difference in the response so provided between students the clinical academic respondents, clinical nonacademic respondents, and research respondents.(11) According to Arpita et al, most of the post graduate students had better knowledge on using MSEXCEL spread sheet for graphical representation of data and software's for statistical analysis of data available on the internet. (12) (13) Harshe et al have conducted a study among medical professionals inclusive of faculty members, results showed that Sixty percent of the participants reported that they skip the "results" section of a research paper and jump to conclusions directly. Seventy percent of the study participants thought only a biostatistician should carry out statistical analyses in a research project. (14)

This study points out that most of the students (90\%) feel that they have better knowledge about Biostatistics during Post graduation training program than during under graduation. This is because during Post graduation they actually get a chance to perform their own research and also understand that Biostatistics has an essential role in clinical decision making.

Historically, clinicians have been reported to demonstrate a lack of confidence when it comes to adopting biostatistics as a tool for medical literature interpretation. (15) Biostatistics sets in a fearful fire when it comes to the application of it in the student's research. This requires a lateral way of approach where the emphasis should be on the areas of threat- that is altering the teaching methods (problem based teaching) and substituting mathematical calculations by computerized statistical packages. This encourages students to perform their statistical analysis without expert guidance.

The limitation of this study is that there is scope for bias in responding to the questionnaire and also this study was limited to only few institutions and the data so obtained was a qualitative and so analysis was purely descriptive in nature. Covering a wider population might provide a more statistically significant data.

\section{Conclusion:}

Our study aimed at demonstrating the attitude and perception of postgraduate students belonging to various universities of Tamilnadu, towards statistics. From the data so obtained we conclude that, though students are interested in the field of research, the fear of statistical analysis and the inefficiency in obtaining legitimate results can inculcate a negative attitude, which can be waived off by providing appropriate training modalities for students and training so provided should be permissive, discussion oriented to elucidate even their ludicrous doubts to improve their confidence to experiment with research.

\section{Acknowledgement:}

We would like to thank our Chairman, the Dean and Principal for their support and guidance to conduct this study. We would also like to thank the Biostatistician for helping us with the statistical analysis. 


\section{References:}

1. Gore AD, Kadam YR, Chavan. PV, Dhumale GB. Application of biostatistics in research by teaching faculty and final-year postgraduate students in colleges of modern medicine: A cross sectional study. Int J App Basic Med Res. 2012; 2(1) : 11-16

2. Ercan I, Yazici B, Yang Y, Ozkaya G, Cangur S, Ediz B, et al . Misusage of statistics in medical research. Eur J Gen Med 2007;4:128-34

3. Ramisetti arpita, Rajasekhar Nutalapati, Chintalapani Srikanth, Jonnalagadda Laxmi Swetha.Cognition , comprehension and application of biostatistics in research by Indian postgraduate students in Periodontics J. Indian. Soc .Periodontol .2014;18:65-68

4. El Tantawi MM .Blogging in a biostatistics and research design graduate dental course:For learning or interaction ? J Dent Edu 2010;74(4):410-416.

5. Liza Lorenza Jala and Enriqueta Reston, University of Cebu, Philippines, University of San Carlos, Philippines. Assessment of Graduate Students' Conception Of Statistical Inference :Philippine Perspective. ICOTS2010;8

6. Shetty AC, Al Rasheed NM, Albwardi SA. Dental professionals attitude towards biostatistics. Journal of Dentistry and Oral Hygiene. 2015 Jul 31;7(7):113-8.

7. Khan N, Mumtaz Y.Attitude of teaching faculty towards statistics at a medical university in Karachi,Pakistan. J Ayub Med Coll Abbottabad 2009;21:3.

8. Morris RW . Does EBM offer the best opportunity yet for teaching medical statistics? Stat Med 2002; 21:96977.

9. Shah SI. Viewpoint:: Pancakes and Medical Statistics. Academic Medicine. 2005 May 1;80(5):452-4. (8)

10. Nowacki AS. Using the 4MAT Framework to Design a problem-based Learning Biostatistics Course. J.Stat.Educ. 2011;19(3):1-24.

11. Batra M, Gupta M, Dany SS, Rajput P. Perception of dental professionals towards biostatistics. International Scholarly Research Notices. 2014 Oct 29;2014.

12. Swetha JL, Arpita R, Srikanth C, Nutalapati R. Cognition, comprehension and application of biostatistics in research by Indian postgraduate students in periodontics. Journal of Indian Society of Periodontology. 2014 Jan;18(1):65.

13. Swetha JL, Arpita R, Srikanth C, Nutalapati R. Cognition, comprehension and application of biostatistics in research by Indian postgraduate students in periodontics. J Indian Soc Periodontol 2014;18:65-8

14. Harshe DG, Abraham DA. A study of attitudes of teaching faculty and postgraduate residents at a tertiary care teaching hospital toward biostatistics. Muller J Med Sci Res 2017;8:10-4.

15. Akinsola OJ, James O, Ibikunle AA, Adeyemo WL. Understanding biostatistics: A study of Nigerian dental resident doctors. Nigerian Journal of Experimental and Clinical Biosciences. 2014 Jul 1;2(2):100. 